\title{
Case report of a 65-year-old man with biatrial metastatic localisation from poorly differentiated cutaneous squamous cell carcinoma
}

\author{
Lorenzo Dottorini ${ }^{1}$, Italo Sarno ${ }^{1}$, Pasquale Scopelliti ${ }^{2}$, Gianluca Cotroneo ${ }^{1}$, Maribel Duluc ${ }^{1}$, Alessandro laculli ${ }^{1}$, Nicola Giuntini ${ }^{1}$, \\ Federica Brena ${ }^{1}$ and Giuseppe Nastasi ${ }^{1}$
}

${ }^{1}$ Oncology Unit, Medical Sciences Department, ASST Bergamo Est, Alzano Lombardo, BG 24022, Italy

${ }^{2}$ Cardiology Unit, Medical Sciences Department, ASST Bergamo Est, Alzano Lombardo, BG 24022, Italy

\begin{abstract}
We report the case of an immunocompetent 65-year-old man affected by cutaneous squamous cell carcinoma (cSCC) with lung and biatrial metastatic localisation. In May 2018, the patient underwent lower limb amputation due to the finding of a large ulceration which upon biopsy was found to be a poorly differentiated squamous cell carcinoma (SCC), ulcerated, full-thickness infiltrating from the skin to the underlying bone tissue. After 1 month, a radiological restaging found multiple pulmonary localisations and a right-atrial metastatic localisation. The patient was then studied in-depth and a transesophageal echocardiogram found that the patient had two 2 and $5 \mathrm{~cm}$ metastatic localisations in the left atrium and a $3-\mathrm{cm}$ metastatic localisation in the right atrium. Informed about the clinical situation and about the risks of a chemotherapeutic treatment, the patient decided not to start any treatment. This case represents, to our knowledge, the only case of a biatrial metastatic localisation from cSCC and is representative of how cardiac symptoms and signs in patients affected by this disease must be evaluated.
\end{abstract}

Keywords: cutaneous, skin, carcinoma, heart, atrial metastases, cancer, biatrial

\section{Background and introduction}

Cutaneous squamous cell carcinoma (cSCC) is the second most common form of nonmelanoma skin cancer after basal cell carcinoma. [1] Its origin is the malignant proliferation of epidermal keratinocytes due to multiple biological events [2, 3]. Previously reported findings showed how immunosuppressed patients tend to develop multiple and more aggressive skin cancer. Patients undergoing solid organ transplantation have a 65-fold higher risk of developing $\mathrm{CSCC}$ than the general population [4-6]. This tumour has a high rate of recurrence and distant metastasis, especially for those patients with tumours involving the lips and ears with frequent involvement of lateral-cervical, submandibular, submental and intraparotid lymph nodes [7]. Cardiac metastatic localisation from cSCC is an extremely rare event and very poor scientific evidence is available. We found no evidence of a double atrial localisation. The case report we described could be the first scientific evidence of this rare occurrence and could help clinicians to evaluate all cardiac symptoms and signs in cSCC patients.
Correspondence to: Lorenzo Dottorini Email: Idottorini@gmail.com

ecancer 2019, 13:977

https://doi.org/10.3332/ecancer.2019.977

Published: $19 / 11 / 2019$

Received: 24/08/2019

Publication costs for this article were supported by ecancer (UK Charity number 1176307).

Copyright: $($ ) the authors; licensee ecancermedicalscience. This is an Open Access article distributed under the terms of the Creative Commons Attribution License (http:// creativecommons.org/licenses/by/3.0), which permits unrestricted use, distribution, and reproduction in any medium, provided the original work is properly cited. 


\section{Case presentation}

In May 2018, an immunocompetent 65-year-old man with no familial history of skin cancer was recovered due to a large ulceration involving the proximal portion of the right leg causing hypofunctionality of the limb and osteomyelitis with loss of neuronal substance. A cutaneous biopsy demonstrated an SCC. The ulceration was too large to be subjected to local excision; therefore, after a complete radiological staging with chest and abdomen computed tomography that did not show distant metastases, amputation of the middle third of the right leg was made. The definitive histological examination showed an ulcerated area of $13 \mathrm{~cm}$, necrotic, haemorrhagic, incorporating and fullthickness infiltrating from skin to the underlying bone tissue, compatible with poorly differentiated SCC. For persistence of secretions, the wound was revised and cleaned several times. One month after amputation, a radiological restaging with chest and abdomen computed tomography showed multiple bilateral lung lesions compatible with distant metastases and a dubious intracardiac nodularity. The patient was then studied for a possible infectious disease but all the exams (including tuberculosis screening) were negative. We performed a fibrobronchoscopy with biopsy of a mediastinal lymph node and bronchioloalveolar lavage, resulting in positive SCC in both samples. The following positron emission tomography highlighted multiple lung localisations (Standardised uptake value 20), widespread skeletal accumulation referable to osteomidullary activity compatible with substitutive meaning and a left and right atrial nodularity compatible with metastases (standardised uptake value 7, 4). Echocardiography revealed a solid lesion on the atrial side of the anterior tricuspid flap; the ejection fraction determined to be $85 \%$. A transesophageal echocardiography documented in the right atrium a voluminous tripartite formation with a sessile spherical base of $3 \mathrm{~cm}$ in diameter and two other non-homogeneous mobile formations of 2 and $5 \mathrm{~cm}$ in diameter, each comes into contact with the atrial margin of the tricuspid valve. In the left atrium, evidence of a roundish $2 \mathrm{~cm}$ diameter formation anchored by a peduncle to the atrial roof was compatible with metastases (Figures 1-5). A cardiac surgery consultation determined that the extent of the disease, including at the pulmonary level, suggested that surgical intervention was inappropriate. A cardiac nuclear magnetic resonance was unsuccessful since the patient experienced rapid dyspnoea that arose from lying in a supine position. Despite the extent of the disease and the cardiac involvement, considering the young age of the patient and the conserved cardiac function, we proposed a platinum-based chemotherapeutic treatment; however, when informed of the possible risks and benefits of the treatment, the patient preferred not to undertake any oncological treatment.

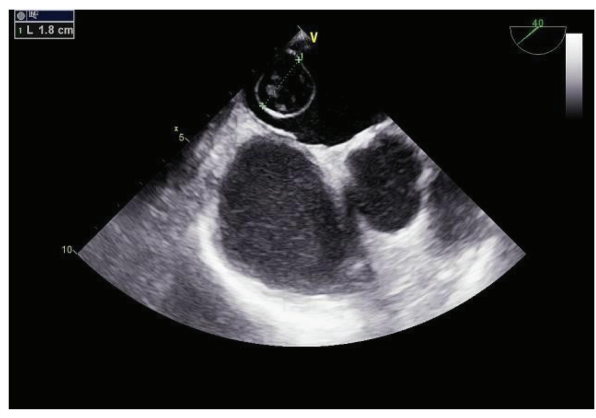

Figure 1: Transesophageal echocardiogram of the mass in the left atrium.

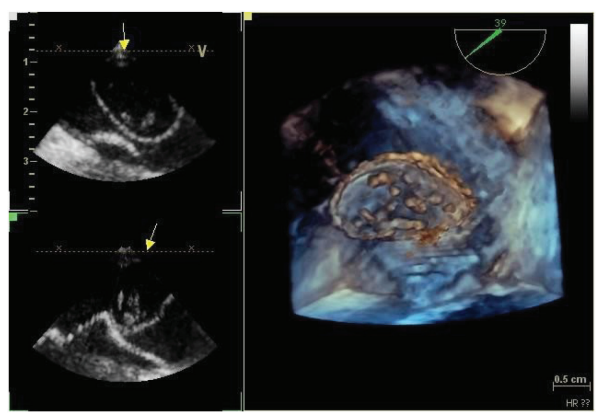

Figure 2: Tridimensional transesophageal echocardiogram of the mass in the left atrium. 


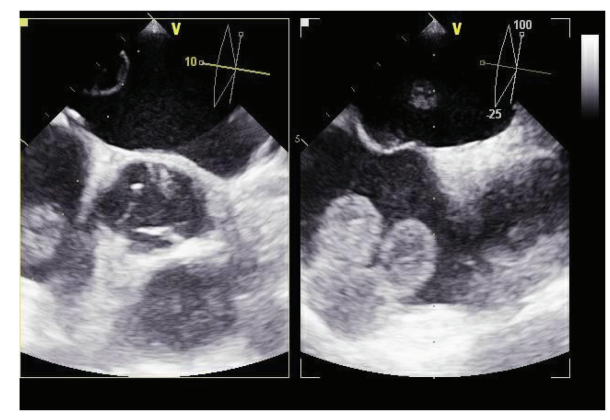

Figure 3: Transesophageal echocardiogram of the mass in the right atrium.

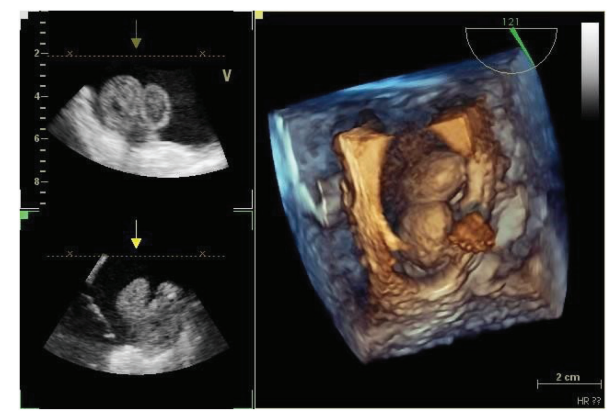

Figure 4: Tridimensional transesophageal echocardiogram of the mass in the right atrium.

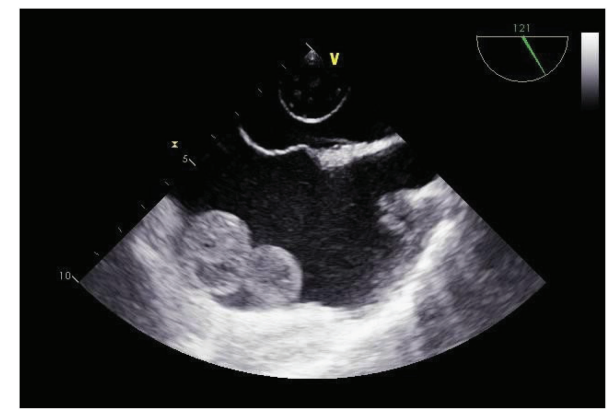

Figure 5: Transesophageal echocardiogram of the mass both in the right and left atria.

\section{Discussion}

Cutaneous carcinomas (basal and squamocellular) derive from epidermal keratinocytes and skin appendages and represent over $90 \%$ of malignant skin tumours [8]. Exposure to UV radiation (especially UVB) is the main risk factor for these neoplasms [9] and the initiator of genetic damage at the base of their development, both through the production of reactive oxygen compounds (ROS), and through the loss of heterozygosity (LOH) of tumour suppressor genes [10]. Other factors involved in the genesis of these lesions are consumption of tobacco (for the squamocellular forms), arsenic, vinyl chloride, polycyclic aromatic hydrocarbons, alkylated agents and exposure to vapours of petrol [11]. Lower risk factors such as immunosuppression (favoured by UVB) and HPV infection (which is often found in immunosuppressed patients) appear in connection with this type of carcinoma. Tumour diameter $(>2.0 \mathrm{~cm}$ ) and perineural involvement (>0.1 mm) are mostly associated with disease-specific death and nodal metastases [12]. Cardiac metastases from cSCC are an event extremely rare and few data are available in the scientific literature. Mackenzie et al [13] published a case report about a myocardial metastasis of cSCC 
in a renal transplant recipient whose cause of death was pulmonary thromboembolism. Boukhalil et al [14] reported a case of cSCC with pericardial metastases, whereas Hunter et al [15] reported a case of right ventricular inflow tract obstruction secondary to cSCC.

\section{Conclusion}

To the best of our knowledge, there are no cases in the scientific literature reporting a metastatic localisation of cSCC in both cardiac atria. Our case report underlines how patients with advanced cancer, including cSCC, presenting cardiac signs and symptoms such as fatigue, arrhythmia, congestive heart failure or cardiac tamponade must always be suspected of having tumour involvement of the heart.

\section{Conflicts of interest}

The authors declare that they have no conflicts of interest.

\section{Funding statement}

No funding was received.

\section{References}

1. Motaparthi K, Kapil JP, and Velazquez EF (2017) Cutaneous squamous cell carcinoma: review of the eighth edition of the American Joint Committee on cancer staging guidelines, prognostic factors, and histopathologic variants Adv Anat Pathol 24(4) 171-194 https://doi. org/10.1097/PAP.0000000000000157 PMID: 28590951

2. Wang W, Jorgenson E, and Whittemore AS, et al (2018) Susceptibility loci-associated cutaneous squamous cell carcinoma invasiveness J Invest Dermatol 138 557-561

3. Nissinen L, Farshchian M, and Riihila P, et al (2016) New perspectives on role of tumor microenvironment in progression of cutaneous squamous cell carcinoma Cell Tissue Res 365(3) 691-702 PMID: 27411692

4. Bonerandi JJ, Beauvillain C, and Caquant L, et al (2011) Guidelines for the diagnosis and treatment of cutaneous squamous cell carcinoma and precursor lesions J Eur Acad Dermatol Venereol 5 1-51

5. Hartevelt MM, Bavinck JN, and Kootte AM, et al (1990) Incidence of skin cancer after renal transplantation in the Netherlands Transplantation 49(3) 506-509 PMID: 2316011

6. Krynitz B, Edgren G, and Lindelof B, et al (2013) Risk of skin cancer and other malignancies in kidney, liver, heart and lung transplant recipients 1970 to 2008--a Swedish population-based study Int J Cancer 132(6) 1429-1438

7. Nissinen L, Farshchian M, and Riihila P, et al (2016) New perspectives on role of tumor microenvironment in progression of cutaneous squamous cell carcinoma Cell Tissue Res 365(3) 691-702 PMID: 27411692

8. AIOM-AIRTUM I numeri del cancro 2018

9. IARC Monographs on the evaluation of carcinogenesis risk to humans. Solar and ultraviolet radiation 55 1-316 1992

10. Bolshakov S, Walker CM, and Strom SS, et al (2003) p53 mutations in human aggressive and nonaggressive basal and squamous cell carcinomas Clin Cancer Res 9 228-234 
11. LeBoit PE, Burg G, and Weedon D, et al (2006) World Health Organization Classification of Tumours. Pathology and Genetics of Skin Tumours (Lyon: IARC Press)

12. Clark JR, Rumcheva P, and Veness MJ (2012) Analysis and comparison of the 7th edition American Joint Committee on Cancer (AJCC) nodal staging system for metastatic cutaneous squamous cell carcinoma of the head and neck Ann Surg Oncol $94252-4258$ https://doi. org/10.1245/s10434-012-2504-2

13. Mackenzie KA, Simcock JW, and Lainchbury JG, et al (2009) Myocardial metastasis of cutaneous squamous cell carcinoma in a renal transplant recipient Transplant Proc 41(10) 4414-4415 PMID: 20005411

14. Boukhalil P and Debek A (2006) Images in clinical medicine N Engl J Med 355 e24 https://doi.org/10.1056/NEJMicm053597

15. Hunter JM, Reid AL, and Stride PJ, et al (2012) Right ventricular inflow tract obstruction secondary to metastatic cutaneous squamous cell carcinoma BMJ Case Rep 2012 https://doi.org/10.1136/bcr-2012-006556 